[Manuscript version. Final paper to appear in Synthese and available online at http://dx.doi.org/10.1007/s11229-015-0702-8]

\title{
Where is the understanding?
}

\author{
Adam Toon \\ University of Exeter \\ a.toon@exeter.ac.uk
}

\begin{abstract}
Recent work in epistemology and philosophy of science has argued that understanding is an important cognitive state that philosophers should seek to analyse. This paper offers a new perspective on understanding by looking to work in philosophy of mind and cognitive science. Understanding is normally taken to be inside the head. I argue that this view is mistaken. Often, understanding is a state that criss-crosses brain, body and world. To support this claim, I draw on extended cognition, a burgeoning framework in cognitive science that stresses the crucial role played by tools, material representations and the wider environment in our cognitive processes. I defend an extended view of understanding against likely objections and argue that it has important consequences for questions concerning the nature of understanding and its relationship to explanation.
\end{abstract}

\section{Keywords}

Understanding - Explanation - Situated Cognition - Extended Cognition - Extended Mind 


\section{Introduction}

Recent philosophy of science has seen a growing interest in scientific understanding. In contrast to explanation, understanding has often been felt to be too subjective to merit sustained discussion by philosophers of science. One reason for this is a tendency to identify understanding with the distinctive Aha! feeling that we often experience when we explain something. However, recent work in both epistemology and philosophy of science has argued that, while it might be accompanied by a distinctive feeling, understanding is an important cognitive state that philosophers should seek to analyse (e.g. Kvanvig 2003; de Regt et al. 2009b). This raises a range of questions. For example, if understanding is a cognitive state, what is the nature of that state? Most authors agree that, in order to understand a phenomenon, a scientist must not only be able to recall relevant facts or theoretical principles; they must also "grasp" or "see" the connections between them (e.g. Elgin 2009; Riggs 2003). What exactly are these acts of "grasping" or "seeing" that seem to be characteristic of understanding (Grimm 2011)? Moreover, if understanding goes beyond being able to provide the facts and principles that explain a phenomenon, then how do explanations provide us with understanding (de Regt et al. 2009a)?

If understanding is a cognitive state, and "grasping" and "seeing" are "psychological acts" (Grimm 2010, p. 342), then it is tempting to assume that they must be found inside the scientists' head. I will argue that this view is mistaken. Understanding is not always in the head. Often, especially when scientists are dealing with complex theories and phenomena, understanding is a state that criss-crosses brain, body and world. To support this view, I draw on recent work in cognitive science and philosophy of mind. Situated cognition is a growing movement in cognitive science that reveals how many cognitive tasks are performed not by internal thought processes alone, but instead rely on skilful exploitation of material representations, tools and the wider environment (e.g. Robbins and Aydede 2009). In light of this work, many philosophers of mind and cognitive science have argued that our cognition, and even our minds, extend beyond our brains and bodies into the world (e.g. Clark and Chalmers 1998). In recent years, a number of authors have 
suggested that work in situated cognition and related areas might provide a fruitful framework for studying scientific reasoning (e.g. Bechtel 1996; Giere 2006; Nersessian 2005; Ylikoski 2009). At the same time, there is now a burgeoning literature within epistemology on the consequences of extended cognition for a range of issues concerning knowledge, such as the relationship between knowledge and cognitive ability (Clark et al. 2012; Pritchard 2010; Vaesen 2011). In this paper, I aim to develop an extended approach to understanding and defend it against a range of likely objections. By doing so, I hope to show that extended cognition has important implications for the questions that we ask about understanding, as well as knowledge.

The discussion will proceed as follows. Section 2 will introduce some key ideas in recent work on understanding in epistemology and philosophy of science. Section 3 will offer a brief overview of situated cognition and the related notions of extended cognition and the extended mind. In Section 4, I will argue that the notion of extended cognition applies not only to explanatory inquiry or the act of giving an explanation, but to understanding itself: the acts of "grasping" and "seeing" taken to be characteristic of understanding often take place not inside the scientist's head, but in processes that include external, material devices. Section 5 responds to some likely objections to this view, while Section 6 considers criticism of the notion of extended cognition in general. Finally, in Section 7, I consider the implications of extended cognition for an alternative conception of understanding, which takes it to be an ability rather than an act of "grasping" or "seeing".

\section{Understanding and explanation}

Stephen Grimm (2011) distinguishes three different questions that we might ask about understanding. To introduce these questions, it is helpful to consider parallels with knowledge. According to a traditional analysis, $S$ knows that $p$ if and only if $p$ is true, $S$ believes that $\mathrm{p}$, and $\mathrm{S}$ is justified in believing that $\mathrm{p}$. On this view, the object of knowledge is a true proposition, the relevant psychological attitude is belief, and the normative requirement is justification. We can ask similar questions about understanding. 
Suppose we say that "S understands P", where P is some natural phenomenon. First, we might ask about the object of understanding. For example, is the object of S's understanding a set of propositions about P? Or is it perhaps a model or some sort of abstract structure representing the phenomenon (Grimm 2011)? Second, we might inquire into the psychology of understanding. For example, does understanding amount to believing a set of propositions about $\mathrm{P}$, or is some other psychological state involved (Grimm 2006, Trout 2007)? Third, we might wonder about the normativity of understanding. Here discussion has focused on whether understanding is subject to the same normative constraints as knowledge. For instance, does understanding require truth? Is it compatible with epistemic luck? (Grimm 2006; Kvanvig 2003)

We may also add a fourth question to Grimm's list. This is the question of the subject of understanding. Here the question is: who (or perhaps what) understands the phenomena? Again, we ask similar questions about knowledge. Often, when we say "S knows p", "S" refers to an individual. But sometimes we attribute knowledge to groups. For example, we might say, "scientists at CERN now know that the Higgs Boson exists". This raises a number of issues. For example, how does group knowledge depend upon the epistemic states of its members (Bird 2010)? Discussions of understanding typically regard the subject of understanding as an individual. For example, although they stress various social aspects of understanding, when considering the subject of understanding, de Regt et al. (2009a, p. 3) write that "this subject is typically a scientist who understands a phenomenon". And yet it seems that we often attribute understanding to groups. For example, we might say that "scientists at CERN now understand why fundamental particles have mass". We might therefore ask similar questions about group understanding to those we ask about group knowledge (Leonelli, forthcoming.)

Let us focus on cases in which we attribute understanding to individuals. What is the psychology of understanding in such cases? Imagine that Tom and Barbara are watching a 
Boeing 747 take off and Tom turns to Barbara and asks "Why do planes fly?"1 Let us suppose that Barbara is an aeronautical engineer and understands why planes fly, but Tom does not. What is the relevant psychological state that characterises Barbara's understanding? What does Barbara possess that Tom does not? One view might be that, in order to understand why planes fly, Barbara must simply know Bernoulli's principle and the relevant details about the plane. On this view, the psychology of understanding is much the same as the psychology of knowledge, namely belief. And yet it seems that Tom might know Bernoulli's principle and the relevant features of the plane, while still not understanding why planes fly. There might be two reasons for this. First, he might know Bernoulli's principle but never have attempted to apply it to the question of why planes fly. (Barbara: "Well, you know Bernoulli's principle" Tom: "Yes, of course, but what's that got to do with it?") Second, even if Tom were to attempt to apply Bernoulli's principle to the question of why planes fly, he might lack the ability to do so (Tom: "OK, I see that Bernoulli's principle might be relevant. But how do I know the speed of the air around the wing?"). As Kuhn and others have pointed out, students are often able to recite important theoretical principles, and yet have no idea how to apply them (Kuhn 1970, pp. 23-51).

Most recent authors on understanding agree that it involves more than simply believing, or even knowing, relevant facts and theoretical principles. Instead, understanding requires that we also "see" or "grasp" how those facts and principles fit together. Thus, Wayne Riggs argues that "[a]n important difference between merely believing a bunch of true statements within subject matter $\mathrm{M}$, and having understanding of $\mathrm{M}$, is that one somehow sees the way things fit together. There is a pattern discerned within all the individual bits of information or knowledge" (Riggs 2003, p. 218). In a similar vein, Catherine Elgin writes that "to understand the Comanches' dominance of the southern plains involves

\footnotetext{
${ }^{1}$ This example is based on Trout (2002) and Grimm (2010).
} 
more than knowing the various truths that belong to a comprehensive, coherent account of the matter. The understander must also grasp how the various truths relate to each other" (Elgin 2009, p. 323). As Grimm (2006) makes clear, "seeing” or "grasping” connections involves more than simply believing that they hold. If an expert tells me that a difference in air pressure generates lift on the wing of the plane, then I might have excellent reason to believe this. And yet it seems that I could assent to this claim while still not "seeing" or "grasping" how the difference in pressure results in lift. Similarly, a mathematics pupil might have reason to believe that each step in a proof follows from the previous one, simply because her teacher tells her so. But the pupil might still not understand the various steps in the proof. While admitting that talk of "seeing" or "grasping" remains largely metaphorical, Grimm (2010) suggests that "grasping" a theoretical principle involves at least two things. First, it involves the ability to apply the principle to the world. Second, it involves the ability to anticipate how a change in one of the variables in the principle leads to changes in the others. The importance of such abilities is also emphasised by a number of other authors, including Elgin (2009) and Henk de Regt (e.g. 2004; see also de Regt and Dieks 2005).

Summing up, it would appear that, if Barbara understands why planes fly, then she must be able to do more than simply recall Bernoulli's principle, recite lists of facts about air pressure, the shape of planes' wings, and so on. In addition, she must also "grasp" or "see" the connections between these things. For example, she must "grasp" how Bernoulli's principle applies to the air flow around the wing, "see" how the difference in air speed will result in a difference in pressure, "see" how the difference in pressure generates lift, and so on. If she properly "grasps" or "sees" these connections, then Barbara does more than simply believe that they hold. She enjoys a richer cognitive achievement, which allows her to put the information she possesses to use in various ways. For example, she is able to answer questions such as "What if a plane's wings were flat, rather than curved?" or "What if a plane tries to fly in a vacuum?" In this way, understanding some phenomenon goes beyond merely possessing the various facts and principles that figure in a correct explanation for that phenomenon. 
If this view of understanding is along the right lines, then we might wonder how understanding relates to explanation. Before we consider this question, it is important to note that the term "explanation" is used in many different ways. If we say "Bernoulli's explanation of why planes fly is true", it seems we are referring to a certain product of scientific inquiry, such as a set of claims. Following Grimm (2010), let us call these explanatory stories. One might think of explanatory stories as abstract entities, such as propositions. In what follows, however, it will sometimes be helpful to refer to the particular, concrete form that an explanatory story might take, such as equations written on a piece of paper. I will call these explanatory inscriptions. Often, though, we use "explanation" to refer not to a product, but to an activity. For example, if we say "Bernoulli's explanation took up half of his lecture" we are referring to what Grimm calls the act of presenting an explanatory story. Finally, notice that we also use "explanation" to mean the activity of coming up with an explanatory story in the first place, rather than that of communicating it to others. Thus, we might say "the proper explanation of flight took scientists many years". Modifying Grimm's terminology slightly, let us call this explanatory inquiry. Notice that an explanatory inquiry might involve searching for an explanatory story that is new to science as a whole, or just to a particular individual or group.

Let us focus in particular on the relationship between understanding and explanatory stories. Philosophers of science have tended to assume that possessing an explanatory story leads automatically to understanding. If understanding were simply a matter of knowing the appropriate principles and background conditions, then presumably gaining understanding would be a fairly straightforward process: the scientist would simply have to remember the appropriate explanatory story. On the other hand, if understanding involves more than belief, then the process by which the scientist gains understanding is likely to be more complicated. As de Regt et al. (2009a, p. 7) put it:

[g]aining understanding through explanations is not an automatic process, but rather a cognitive achievement in its own right [...] Once it is granted that deriving understanding from an explanation is a matter of ability, the 
question arises of how that actually works. What are the mechanisms through which scientists extract understanding from explanations that they already possess?

We will return to this question in Section 4. For the moment, the important point is that there is now widespread agreement that understanding is not merely an Aha! feeling but also an important cognitive state that merits the attention of epistemologists and philosophers of science. In the next section, I will introduce a burgeoning movement in cognitive science that I think can help us to make sense of the cognitive component of understanding.

\section{Situated and extended cognition}

'Situated cognition' is the name given to a growing body of work in cognitive science that stresses the importance of interaction between the brain, body and environment in carrying out cognitive tasks. Along with related approaches, such as embodied cognition and distributed cognition, work in situated cognition encompasses a wide range of different disciplines, from anthropology to robotics (for an overview, see Robbins and Aydede 2009). Although it is not possible to survey this vast literature here, the main ideas may be gleaned by considering a canonical example of situated cognition, namely multiplication using pen and paper.

According to neural network models, our brains are good at tasks such as recognising and completing patterns, not sequential or logical reasoning. And yet we are able to perform such reasoning. How do we manage this? In a highly influential treatment, Rumelhart et al. (1986, pp. 44-48) argue that the answer lies in our use of external, material representations. Suppose that you are asked to multiply two three-digit numbers (e.g. 567 $x$ 843). Most people cannot do this in their head. The task becomes a lot easier if we are given a pen and paper, however. For example, we might use the method of long multiplication, lining up the numbers carefully one underneath the other, then working step-by-step through the procedure and writing down the intermediate products as we go. 
By manipulating our external, material environment in this way, we reduce a complex task to a series of much simpler ones (e.g., remembering $3 \times$, writing numbers in neat columns, and so on), each of which can be accomplished by brains that are suited to pattern recognition. Thus, we are able to carry out sequential or logical reasoning tasks, such as multiplying three-digit numbers. But such tasks are often accomplished not only by our brains, but by interaction with the external environment.

Situated cognition suggests that much of our cognitive activity has a similar character to multiplication with pen and paper, involving interaction between brain, body and world. This idea has provoked a lively debate within recent philosophy of mind and cognitive science. Impressed by the pervasive role that external devices play within our lives, a number of authors have endorsed the hypothesis of extended cognition (HEC). Although HEC is perhaps most often associated with Andy Clark (e.g. 2008), related positions have also been defended by Richard Menary (2007), Mark Rowlands (1999), Mike Wheeler (2005), Robert Wilson (2004) and others. According to HEC, external devices such as diaries, laptops and phones can, and often do, become part of our cognitive processes. On this view, the pen and paper that we use in long multiplication is part of the mechanism that realises our cognition, just like the neurons in our brain. Wilson and Clark (2009, p. 65 ) introduce the notion of a "transient extended cognitive system" (TECS). A TECS is "a soft-assembled whole that meshes the problem-solving contributions of the human brain and central nervous system with those of the (rest of the) body and various elements of the local cognitive scaffolding" (ibid.). Notice that, although TECS are transient, they are often regularly repeated. Multiplication with pen and paper is a case in point: we might follow a similar procedure whenever we multiply long numbers, even if we use a new piece of paper each time and discard it seconds later. Similarly, a seasoned solver of crossword puzzles might always reach for pen and paper to run through her usual routine of jumbling up letters to spot anagrams (ibid.). In Wilson and Clark's view, TECS are extremely important. In fact, "the bulk of real-world problem solving, especially of the kinds apparently unique to our species, may be nothing but the play of representation and computation across these spectacularly transformative mixes of organismic and 
extranorganismic resources [i.e. TECS]" (2009, p. 73).

Many advocates of HEC are also defenders of the extended mind thesis. Indeed, according to Wilson and Clark, "the notion of an extended mind is nothing more than the notion of a cognitive extension $[\ldots]$ that scores rather higher on the $[\ldots]$ dimension of durability and reliability" (2009, p. 66). Clark and Chalmers (1998) offer the famous example of Otto and Inga. When Inga hears of an exhibition at the Museum of Modern Art she recalls that the museum is on 53rd Street, and sets off. Otto is an Alzheimer's patient who carries a notebook wherever he goes to record useful information and trusts what it says without question. When Otto hears about the exhibition, he looks up the information in his notebook, and sets off. According to Clark and Chalmers, Otto's notebook plays a similar functional role in his life as Inga's biological memory does in hers. As a result, they argue, the notebook is part of the material basis that realises Otto's standing beliefs. Otto believes that the exhibition is on 53rd Street even before he looks at his notebook, just as Inga believes this even before consulting her memory. If standing beliefs count as part of our minds, then it seems that Otto's mind extends beyond his head and body and into the world.

Together, HEC and the extended mind thesis have radical implications for deep-seated views of the nature of mind and cognition. In what follows, I will argue that they also have important consequences for our view of the nature of understanding. One might think that making this point would require little further argument. After all, if we accept that cognition and mind are extended, then surely it follows immediately that understanding is extended. This is too quick, however. What Clark and Chalmers (1998) aim to establish is that, as Clark (2010, p. 82) puts it, "in fairly easily imaginable circumstances - ones that involved no giant leaps of technology or technique - we would be justified in holding that certain mental and cognitive states extended [...] into the nonbiological world". Clark and Chalmers argue for this claim by offering a putative case of extended belief, namely Otto and his notebook. Even if we accept this argument, however, we are still left with the question of what other cognitive states might be extended (if any) and how widespread such extensions are. Moreover, as we will see, the 
notion of extended understanding might be thought to be especially problematic in ways that talk of other extended states, such as extended beliefs, is not. In the following section, then, I aim to show that understanding can be an extended state and that, in fact, cases of extended understanding are fairly commonplace. Afterwards, in Section 5, I will respond to a range of objections to the notion of extended understanding.

\section{$4 \quad$ Extended understanding}

How might the notion of extended cognition apply to understanding? Recall the different senses of "explanation" discussed in Section 2. Clearly, it would be uncontroversial to claim that explanatory inquiry often involves external representations, tools, instruments and other material devices. Perhaps, then, we might try to develop an extended account of this inquiry, showing the way in which tools and external representations extend and transform scientists' reasoning processes. It would also be uncontroversial to claim that external representations are involved in the act of giving an explanatory story, so extended cognition might also have something to offer here too. In this section, however, I want to argue for a more controversial claim, which is that tools, external representations and other material scaffoldings are involved not only in explanatory inquiry or the act of giving an explanatory story but also in understanding itself. In other words, I want to argue that the cognitive state that epistemologists and philosophers of science have taken to be characteristic of understanding is often realised not inside the scientists' head, but in an extended system that includes external, material devices.

Consider Tom and Barbara again. Let us now suppose that, instead of asking simply "Why do planes fly?", Tom asks Barbara a more difficult why-question, such as "Why do planes experience Dutch roll'? Dutch roll is a complex oscillatory motion that planes experience when flying through turbulence (apparently named after the rhythmic motion executed by Dutch skaters). According to the Aerospace Engineering Desk Reference, "[t]he Dutch roll mode is a classical damped oscillation in yaw [...] which couples into roll and, to a lesser extent, into sideslip. The motion described by the Dutch roll mode is 
therefore a complex interaction between all three lateral-directional degrees of freedom. Its characteristics are described by the pair of complex roots in the characteristic polynomial" (2009, p. 235). The equations of motion that figure in the explanation of Dutch roll are complex and cover an entire page in the lecture notes for MIT's graduate course "Aircraft Stability and Control” (How, 2004). Both the Aerospace Engineering Desk Reference and MIT's lecture notes include four pairs of diagrams, each showing a top and rear view of a plane, indicating the sequence of steps involved in a typical Dutch roll cycle. Next to these diagrams is series of notes, along with a graph showing how the angle of the wings and nose of the plane vary during the cycle.

Let us assume that Barbara's training included lectures on Dutch roll. When she hears Tom's question, Barbara remembers these lectures clearly and is able to recall the theoretical principles required to explain Dutch roll, along with the relevant facts about the plane. At this point, however, Barbara resorts to pen and paper. She first writes down some (highly simplified) equations that capture the essence of the relevant theoretical principles. Then she draws a quick sketch of a plane tilted to one side and considers how the principles apply in this case. As she does so, Barbara draws small arrows around the wings, showing how she would expect the aircraft to move, and then draws another quick sketch of the plane showing its position a moment later. Perhaps, like the MIT lecture notes, she might also draw a rough graph, showing how the angle of the wings changes over time. In this way, let us assume, Barbara is able to apply the relevant theoretical principles to explain Dutch roll. On the other hand, let us also assume that, if she does not have access to pen and paper, Barbara might be able to recall the relevant facts and principles but she cannot work through the steps required to connect the two together. Indeed, she might even be unable to anticipate the effects of qualitative changes in variables unless she first writes down the relevant equations so that she can inspect them, annotate them with arrows, cross out particular terms if their effects are negligible, and so on.

What should we make of this? The key point to notice, I think, is that we would have no hesitation in speaking of understanding in such cases. Barbara certainly understands 
Dutch roll. She knows the relevant facts and theoretical principles. What is more, for Barbara these facts and principles are not merely isolated or unrelated islands of knowledge. Instead, Barbara also "sees" or "grasps" the connections between these two things: she "sees" or "grasps" how the theoretical principles apply to the facts about the plane to bring about Dutch roll. For example, Barbara "sees" how a crosswind might lead the plane to yaw to port, "grasps" how this results in more lift on the starboard wing, "sees" how this causes the plane to roll to port, and so on. It is just that these acts of "seeing" or "grasping" do not happen entirely inside Barbara's head. Instead, they involve literal, rather than merely metaphorical, acts of grasping and seeing, namely those she carries out in creating, manipulating and inspecting external, material representations. For Barbara, understanding Dutch roll is rather like multiplying three-digit numbers or solving a crossword puzzle: it requires interaction with external, material devices.

Of course, the story I have just told about Barbara is a hypothetical one. Empirical work would be required to determine whether it offers an accurate characterisation of scientists' cognitive abilities. Nevertheless, I think Barbara's case is certainly plausible. As we have seen, many recent authors on understanding agree that it is a form of cognitive state that goes beyond merely possessing relevant information; instead, someone who understands can also "see" the connections or patterns that tie this information together. For simple theories or phenomena, this might be something that scientists can do in their heads. In many instances, however, this richer cognitive achievement will be something that the scientist can accomplish only through interacting with tools and external representations. In this way, Barbara's cognitive achievement goes beyond merely possessing the relevant facts and principles, encompassing the richer cognitive state taken to be characteristic of understanding. In order to achieve this, however, Barbara makes use of external, material devices. To use the terminology introduced in Section 3, Barbara's understanding of Dutch roll relies on transient extended cognitive systems (TECS), including equations, diagrams and graphs.

If this view is along the right lines, then extended cognition will have important implications for a number of the issues introduced in Section 2. First, consider the subject 
of understanding. As we saw, existing discussions typically take the subject of understanding to be an individual scientist, rather than a group. However, an extended approach suggests that, even in cases in which we attribute understanding to individuals, the material basis that realises their understanding is not confined to the individual's head, but also includes external, material devices. Perhaps the reason that it is so easy to overlook this fact is that our normal attributions of understanding take place in environments that are thoroughly saturated with material scaffolding that supports our cognitive processes. This scaffolding is so ubiquitous that it is simply taken for granted. Unlike Otto, Barbara might not carry pen and paper with her wherever she goes in case she is quizzed about Dutch roll. Nevertheless, the machinery that Barbara uses for constructing her TECS is available almost anywhere, whether she is at her desk, laboratory bench, or even at the airport.

Next, consider the psychology of understanding. As we have seen, it is commonly acknowledged that understanding the connections between various facts or principles goes beyond believing that they hold. Tom might come to believe that a crosswind leads to Dutch roll because he trusts Barbara's expertise, while still not understanding it. As a result, a number of authors have suggested that an important challenge for theories of understanding is to move beyond metaphors of "grasping" and "seeing" to offer a fuller characterisation of the psychological acts involved in understanding (e.g. Grimm 2011). From the perspective of extended cognition, we can see that the difference between (mere) belief and understanding is likely to lie in an assortment of different cognitive acts that are involved in scientists' interactions with external, material devices, such as motor control, perceptual recognition and pattern-matching capabilities, as well as features of the devices themselves. As a result, an extended view would have important methodological implications for the way that we go about conducting empirical studies into the psychology of understanding, since it suggests the need to study scientists' understanding against its normal background of tools and representational devices in the laboratory, rather than in artificial experimental scenarios.

Finally, consider the relationship between understanding and explanation. Recall that here 
the question was: how do explanatory stories provide us with understanding? Even those who take understanding to involve more than knowing relevant facts and principles often describe the move from possessing an explanatory story to gaining understanding as a matter of "internalisation". For example, like Kuhn and others, Philip Kitcher (1989, p. 438) argues that understanding requires "an extra cognitive ingredient" over and above simply knowing a theory's principles. In Kitcher's view, however, this additional ingredient is to be found in the "internalisation of the argument patterns" associated with the theory (ibid.). Extended cognition suggests that this talk of "internalisation" should be handled with care, however. Earlier I proposed that we use the term explanatory inscriptions to refer to the particular, concrete form that explanatory stories may take, such as equations, graphs or diagrams scribbled on paper. From the perspective of extended cognition, moving from an appropriate explanatory story to understanding is not a matter of internalising that explanatory story, but of learning how to interact in the right way with explanatory inscriptions. ${ }^{2}$

\section{Objections}

There are a number of objections that might be made to the argument so far. One response would be to deny that Barbara understands Dutch roll. We might try to motivate this response simply by pointing to her use of external devices. Thus, it might be said that, if someone needs to resort to scribbling down equations, diagrams, graphs and so on to see how a theory applies to some phenomenon, then they don't really understand that phenomenon. Put in this way, however, the objection is hardly compelling. Would we say

${ }^{2}$ Of course, these remarks are not intended as a wholesale rejection of Kitcher's account. It may well be that Kitcher himself did not intend talk of "internalisation" to be taken too seriously and would be sympathetic to a view along the lines suggested. Thanks to Arnon Levy for discussion on this point. 
that someone can't do arithmetic simply because they need to use pen and paper? Of course, we might say that they can't do mental arithmetic. But why should it be a criterion for possessing scientific understanding that we should do without tools and material representations? If extended cognition is along the right lines, then an enormous amount of our cognitive activity relies on interaction with material devices and environmental props. Given the ubiquity of such devices within scientific practice in particular, it is difficult to see why we would insist that they play no part in scientific understanding. Moreover, as I have suggested already, given the complexity of the theories, data and phenomena that scientists are interested in, dependence on external devices is likely to be the norm, rather than the exception. If we insist that understanding take place in the absence of any material support, then we may well be forced to conclude that scientists understand much less of the world than we think.

One way to try to motivate the claim that Barbara lacks understanding would be to draw on the contrast between understanding and following a procedure by rote. Thus, we might argue that, since she needs to rely on written equations, diagrams, graphs and so on, Barbara is simply following a certain procedure to arrive at the required solution, and this is not enough to show that she possesses understanding. This reply mischaracterises Barbara's abilities, however. It is perfectly true that being able to follow a procedure by rote does not demonstrate understanding. Someone who blindly follows a set of instructions is unlikely to be able to react to changes or interruptions, anticipate what might happen in different circumstances, and so on. But Barbara might be able to do all of these things. If Tom asked, "What if the wings were swept backwards like on a military jet?", Barbara might be perfectly capable of applying the relevant principles to this new scenario and "seeing" how swept back wings would change the outcome. As before, she might simply be unable to do this without relying on external devices. On the other hand, someone could memorise a procedure and follow it without relying upon any external props, and yet we would still not say they possessed understanding.

Another possible response to the claim that understanding is extended would be to suggest that I have misinterpreted Barbara's actions. When she writes down various 
equations, diagrams and graphs, it might be argued, Barbara is simply using these devices to explain Dutch roll to Tom. Barbara's interactions with these external representations are not part of her "grasp" of Dutch roll at all, but simply part of her act of giving an explanatory story. On this view, Barbara's formulas and diagrams play a merely communicative role, while her reasoning process itself takes place entirely inside her head. The difficulty with arguing in this way, of course, is that it amounts simply to denying the main thrust of work in situated cognition, namely that tools and external devices sometimes play an important role in the reasoning process itself. When we multiply two three-digit numbers using pen and paper, the argument goes, the paper isn't merely recording our internal processes. Instead, it is radically transforming the nature of the cognitive task that we must carry out. Similarly, a situated approach to understanding would suggest that the various equations, diagrams and graphs that Barbara constructs do not merely serve to communicate her thoughts to Tom. Instead, interacting with these external representations plays a key role in enabling her "grasp" of the phenomena. Of course, the success of this approach has yet to be seen, and it will take detailed empirical work to determine precisely how external devices support scientists' understanding. But we certainly cannot simply assume at the outset that these devices serve only a communicative function.

Rather than arguing that Barbara's actions should be seen as the act of giving an explanatory story, we might instead claim that they are part of an explanatory inquiry. Even though she encountered the explanatory story for Dutch roll in her training, it might be argued, Barbara resorts to pen and paper because she has forgotten that story and must re-discover it. On this view, extended cognition might have a lot to say about explanatory inquiry, but understanding itself would remain an entirely internal matter. The problem with arguing in this way, however, is that it would seem to show too much. When Tom asks "Why do planes fly?" Barbara might first recall Bernoulli's principle, then think for a moment before bringing to mind an image of a wing and "seeing" how lift results. Let us suppose that Barbara can do this entirely in her head. Would we say that, because she had to go through this thought process, Barbara did not understand why planes fly after 
all? This would seem to make our understanding of any phenomenon far too fleeting, disappearing whenever we are not consciously attending to it. Of course, if someone assures us that they do understand why planes fly but then has to rack their brains for half an hour before coming up with the answer, we might begin to wonder whether they had really understood it in the first place. Once again, however, this has little to do with whether they rely on external props or not. When she hears Tom ask about Dutch roll, Barbara might begin writing and drawing immediately, without any uncertainty or hesitation.

An alternative response begins by drawing a distinction between explicit and implicit understanding. ${ }^{3}$ While explicit understanding is a cognitive state of "seeing" or "grasping", implicit understanding might be seen as the disposition to achieve this cognitive state under certain circumstances. Before performing her calculations, the objection goes, Barbara possesses an implicit understanding of Dutch roll. Afterwards, she gains an explicit understanding. Once achieved, however, this explicit understanding is an entirely internal matter and the pen and paper may safely be discarded. Having pen and paper to hand is simply part of the stimulus conditions required for the disposition to be manifested, much like the presence of oxygen in the room. The difficulty with this line of argument is that, once again, it appears simply to deny the main claim of work in situated cognitive science, which is that external and internal processes often operate together when we carry out cognitive tasks. In our example, Barbara connects together the relevant facts and theoretical principles by manipulating various external representations, such as equations, diagrams and graphs. Why should we assume that, at some point in this interaction, these external representations are copied into some internal representational medium, yielding a "grasp" of Dutch roll that is entirely inside the head?

${ }^{3}$ I am grateful to an anonymous referee for suggesting this line of argument. The exact formulation is my own. 
Taking a different tack, a critic of the notion of extended understanding might ask where we ought to draw the line. As we have seen, understanding is commonly taken to be a cognitive state that involves possessing various items of knowledge (or perhaps merely belief) and "seeing" or "grasping" the connections between them. In Barbara's case, I have argued, "seeing" or "grasping" Dutch roll is (partly) external, while her knowledge remains an internal matter (she is able to recall the relevant principles without props). What if Barbara had to rely on a prompt card to recall the relevant equations instead? Would we still be willing to attribute understanding to her? In some cases, I'm inclined to say that we would. But now a critic might ask how far we are willing to go. Suppose that Tom is simply sitting at his computer with the web address for MIT's online course in aeronautics to hand. We would surely not want to say that Tom understands Dutch roll. And yet it seems that he has access to all the relevant information and, given sufficient time, he might well be able to work through the course and come to "grasp" how the relevant principles apply. How is the proponent of extended understanding to rule out such cases?

Delineating the boundaries of cognition is an important challenge facing all theories of extended cognition, and I cannot hope to offer a definitive answer here (e.g. Rupert 2004; Sprevak 2009; Clark 2008). It is possible to offer some rough and ready considerations, however. If understanding requires believing the relevant facts and principles, then the criteria for extended understanding will be at least as strict as the criteria for extended belief. Clark and Chalmers (1998) look to capture these criteria in what are often referred to as conditions of "glue and trust" (Clark 2010). These conditions require that, like biological memory, an external device must be reliably available and typically invoked, easily accessible whenever required and automatically endorsed (Clark and Chalmers 1998, p. 17; see also Clark 2010 p. 46). Even if he always carries his computer with him and its internet connection is highly reliable, the information that Tom can access on Dutch roll is unlikely to be easily accessible to him or automatically endorsed, especially if he has to rely on a range of other sources in order to work through it. There will also be further conditions for extended understanding. As we noted earlier, if we ask someone a 
why-question and they take a long time to respond, or are extremely hesitant or uncertain in their answer, then we are less inclined to attribute understanding, meaning that Tom is likely fall short in this regard as well.

Finally, one reason why we might feel some resistance to the idea that understanding is not in the head concerns the phenomenological aspect of understanding. As we have noted already, understanding often involves a distinctive Aha! feeling that we experience when the penny finally drops and we come to understand some phenomenon. Understanding something just feels different to merely knowing things about it. If understanding involves a distinctive feeling then it might be argued that, unlike multiplying three-digit numbers or solving crosswords, it cannot be extended outside the head. After all, we feel things in our heads or bodies, not in the pen and paper. On closer inspection, however, this line of thought is not convincing. As we saw in Section 2, recent discussions in both epistemology and philosophy of science have argued that, even if it is often accompanied by an Aha! feeling, understanding is first and foremost a cognitive state. As Grimm puts it, "there is a distinction to be made between the psychological act of "grasping" or "seeing" that seems to be fundamental to understanding, and the phenomenology that accompanies the act" (2010, p. 342). If we accept this view, then it seems that we might grant that the phenomenology accompanying understanding remains internal to the scientist, while still recognising that understanding itself - that is, the cognitive state of "grasping" or "seeing" - extends into the world.

\section{$6 \quad$ Extended or embedded?}

For proponents of HEC, situated cognition shows that cognition extends beyond the head into the body and environment. Not all commentators who are sympathetic to situated cognition are also advocates of HEC, however. As an alternative to HEC, Rupert (2004) introduces the hypothesis of embedded cognition (HEMC). According to HEMC, "Cognitive processes depend very heavily, and in hitherto unexpected ways, on organismically external props and devices and on the structure of the external 
environment in which cognition takes place" (Rupert 2004, p. 393). Like HEC, then, HEMC acknowledges the profound importance of external devices for our cognitive processes. Unlike HEC, however, HEMC stops short of claiming that those external devices are cognitive (or mental). Instead, according to HEMC, cognition (and the mind) remains inside the head. On this view, TECS are hybrid systems, involving both cognitive and non-cognitive elements: the pen and paper are crucial to explaining how are able to carry out tasks like multiplying three-digit numbers, but they are not part of our cognitive processes. Notice that, although less radical than HEC, HEMC shares many of its important theoretical and methodological consequences, since it also emphasises the role played by external devices and radically alters our view of what happens inside our head when we carry out cognitive tasks.

Both HEC and HEMC thus agree that much of our cognitive activity depends upon the interaction of internal and external elements, including the brain, body and environment. The point at issue between them concerns which of these elements count as cognitive (or mental). I cannot hope to settle this debate here (for an overview, see Menary 2010). Instead, my aim in this paper has been to argue that understanding offers another example of the crucial role that external devices play in our cognitive lives. Understanding, like multiplication, is not always in the head. Fortunately, this is something that proponents of both HEC and HEMC can agree on. What they will disagree over is how this should be interpreted. HEC will claim that understanding is a cognitive state that extends outside the scientists' head. By contrast, HEMC will claim that only that which takes place inside the scientists' head deserves to be counted as cognitive. On this view, Barbara's

understanding of Dutch roll turns out not to be a cognitive state after all, but a hybrid state involving cognitive and non-cognitive parts. On either interpretation, however, the proper object of study for epistemologists and philosophers of science who wish to study understanding will not be confined to the scientist's head.

Although I have favoured the interpretation given by HEC, I cannot hope to argue decisively for this view here. I do, however, wish to point out that understanding may provide a particularly useful arena in which proponents of HEC might press their case. 
Often, putative examples of extended cognition are subject to conflicting intuitions. Some are happy to say that Otto believes (or knows) the information written in his notebook, while others are not. In this context, one of the principal advantages of HEMC over HEC is said to be that, by taking only what happens inside the head to be cognitive, it accords better with common sense and avoids uncomfortable extensions of our everyday mental concepts in cases like Otto's. Once we shift our focus from belief (or knowledge) to understanding, however, the situation changes. In contrast to our conflicting intuitions over Otto, I have suggested, we have no hesitation in attributing understanding to Barbara. Our normal concept of understanding applies perfectly well in such cases. Of course, this does not settle the debate between HEC and HEMC. But it may provide further support to those who wish to argue for HEC by appealing to our everyday psychological concepts (e.g. Clark 2011).

\section{$7 \quad$ Understanding as an ability}

Throughout the discussion so far, I have followed the characterisation of understanding found in much recent literature in epistemology and philosophy of science, which takes it to be a cognitive state that involves possessing various items of knowledge (or perhaps merely belief) and "seeing" or "grasping" the connections between them. If we construe understanding in this way, I have argued, it will often be an extended state that depends upon both internal and external elements. Sometimes, however, we find understanding characterised in rather different terms, as an ability to do various things, such as apply theoretical principles to the world (e.g. Chang 2009, Ylikoski 2009). What are the implications of extended cognition for this conception of understanding?

If understanding is seen as an ability, then what Barbara's case would seem to show is that we are willing to attribute understanding even where someone's ability to carry out the relevant tasks depends heavily on the use of external devices. Put this way, however, we might seem to be led back to internalism. After all, it might be argued, it is Barbara herself who has the ability to apply the theory, even if she needs to rely on external props 
to do so. We need to be careful here, however. There are at least two different ways to interpret the ability view. The first construes understanding in (broadly speaking) behaviourist terms. On this view, understanding isn't any underlying cognitive state or process; instead, to possess understanding is simply to exhibit the relevant sorts of behaviours, such as applying formulas successfully (cf. Ylikoski 2009). On this reading of the ability view, it won't make sense to ask whether understanding is internal or external (at least not in the sense at stake in disputes over extended cognition). On a second, alternative reading of the ability view, understanding is not seen in behavioural terms, but as a cognitive state or process that underpins the scientist's ability to carry out the relevant tasks. As we have seen, in cases like Barbara's, external devices are crucial for enabling her to accomplish these tasks. But the internalist might argue that these devices are merely part of the context in which Barbara exercises her ability, not part of the material basis of the ability itself. Notice, however, that, on this approach, understanding is no longer a distinctive state of "seeing" or "grasping", but instead becomes a variety of different cognitive states or processes in different contexts. If Barbara makes heavy use of diagrams, for example, then her understanding might be identified with various sorts of visual reasoning. If instead she were to rely on formulas, then her understanding of Dutch roll might turn out to be a rather different sort of cognitive state or process. This internalist reading of the ability view would therefore seem to come at the cost of sacrificing the unity afforded by an extended perspective. Moreover, even if we view understanding itself as internal in this way, the cognitive processes that Barbara engages in when she applies the principles to explain Dutch roll will still be extended out into the world. ${ }^{4}$

${ }^{4}$ I would like to thank two anonymous referees for urging me to consider the implications of extended cognition for the ability view of understanding. Thanks also to Tom Roberts for very helpful discussion on this issue. 


\section{Conclusion}

Extended cognition proposes a radical change to our view of cognition and mind. I have argued that it should also transform our view of the nature of understanding.

Understanding is not always in the head. Instead, it involves brain, body and world. This extended view of understanding changes our perspective on many issues, including the subject of understanding, the psychology of understanding, and the relationship between understanding and explanation. Epistemologists have already begun to explore a range of areas in which extended cognition may impact upon theories of knowledge. If the argument in this paper is along the right lines, then the implications for inquiries into understanding will be equally far-reaching.

\section{Acknowledgements}

I would like to thank the editors, Raphael van Riel and Markus Eronen, for inviting me to take part in the extremely enjoyable and stimulating workshop on "Understanding Through Modelling” at the Ruhr-Universität Bochum, which gave rise to this special issue. Thanks also to Giovanna Colombetti, John Dupré, Sabina Leonelli, Arnon Levy, Tom Roberts, Juha Saatsi, and two anonymous referees, for very helpful discussion of the ideas in this paper, as well as audiences at the 41st Annual Philosophy of Science Conference at the Inter-University Centre in Dubrovnik, April 14-18th 2014, a Departmental Seminar at the University of Exeter, May 19th 2014, the workshop on "Modelling, Simulating and Experimenting" at the University of Geneva, June 27-28th 2014, and the annual conference of the British Society for the Philosophy of Science at the University of Cambridge, July 10-11th 2014. This project has received funding from the European Union's Seventh Framework Programme for research, technological development and demonstration under grant agreement no. 331432. 


\section{References}

Bechtel, W. (1996). What Should a Connectionist Philosophy of Science Look Like? In R. McCauley (Ed.) The Churchlands and Their Critics. Blackwell.

Bird, A. (2010). Social Knowing: The Social Sense of "Scientific Knowledge".

Philosophical Perspectives 24(1): 23-56.

Clark, A. (2008). Supersizing the mind. Oxford: Oxford University Press.

Clark, A. (2010). Coupling, Constitution, and the Cognitive Kind: A Reply to Adams and Aizawa. In. R. Menary (Ed.) The Extended Mind (pp. 81-100). Cambridge, MA: MIT Press.

Clark, A. (2011). Finding the Mind. Philosophical Studies, 152(3), 447-461.

Clark, A. \& Chalmers, D. (1998). The Extended Mind. Analysis, 58(1), 7-19.

Clark, A., Pritchard, D. \& Vaesen, K. (Eds.). (2012). Extended cognition and epistemology [Special issue]. Philosophical Explorations, 15(2).

Cook, M., Curtis, H. D., De Florio, F., Filippone, A., Jenkinson, L., Marchman, J., Megson, T.H.G., Tooley, M., Watkinson, J. \& Wyatt, D. (2009). Aerospace Engineering Desk Reference. Oxford: Butterworth-Heinemann.

de Regt, H. (2004). Discussion Note: Making Sense of Understanding. Philosophy of Science 71(1): 98-109.

de Regt, H. \& Dieks, D. (2005). A Contextual Approach to Scientific Understanding. Synthese 144(1): 137-70.

de Regt, H., Leonelli, S. \& Eigner, K. (2009a). "Focusing on Scientific Understanding", in H. de Regt, S. Leonelli \& K. Eigner (Eds.) Scientific Understanding: Philosophical Perspectives (pp. 1-17). Pittsburgh University Press.

de Regt, H., Leonelli, S. \& Eigner, K. (eds.) (2009b). Scientific Understanding: Philosophical Perspectives. Pittsburgh University Press. 
Elgin, C. (2009). Is Understanding Factive? In D. Pritchard, A. Millar, \& A. Haddock (Eds.), Epistemic Value (pp. 322-329). Oxford: Oxford University Press.

Estany, A. \& Sturm, T. (Eds.) (2014). The extended cognition thesis: Its significance for the philosophy of (cognitive) science [Special issue]. Philosophical Psychology, 27(1).

Giere, R. (2006) Scientific Perspectivism. Chicago University Press.

Grimm, Stephen R. Is Understanding A Species Of Knowledge? British Journal for the Philosophy of Science 57(3): 515-535.

Grimm, S. (2010). The Goal of Explanation. Studies in History and Philosophy of Science. 41(4): 337-344.

Grimm, S. (2011). Understanding. In S. Bernecker \& D. Pritchard (Eds.), The Routledge Companion to Epistemology (pp. 84-94). New York: Routledge.

How, J. (2004). Aircraft Stability and Control. MIT OpenCourseWare: Massachusetts Institute of Technology. http://ocw.mit.edu/courses/aeronautics-and-astronautics/16-333aircraft-stability-and-control-fall-2004. Accessed 7 Mar, 2014. License: Creative Commons BY-NC-SA.

Kitcher, P. (1989). Explanatory Unification and the Causal Structure of the World. In P. Kitcher \& W. C. Salmon (Eds.), Scientific Explanation (pp. 410-505). Minneapolis: University of Minnesota.

Kuhn, T. S. (1970). The Structure of Scientific Revolutions. Chicago: University of Chicago Press.

Kvanvig, J. (2003). The Value of Knowledge and the Pursuit of Understanding. Cambridge: Cambridge University Press.

Leonelli, S. (forthcoming). Data Interpretation in the Digital Age, to appear in Perspectives on Science

Menary, R. (2007). Cognitive integration: mind and cognition unbounded. Basingstoke: Palgrave Macmillan. 
Menary, R. (Ed.) (2010). The Extended Mind. Cambridge, MA: MIT Press.

Nersessian, N. (2005). Interpreting scientific and engineering practices: Integrating the cognitive, social, and cultural dimensions. In M. Gorman, R. Tweney, D. Gooding, \& A. Kincannon (Eds.), Scientific and technological thinking (pp. 17-56). Erlbaum.

Pritchard, D. (2010). Cognitive ability and the extended cognition thesis. Synthese, 175(1), 133-151.

Riggs, W. (2003). Understanding "Virtue" and the Virtue of Understanding. In M. DePaul \& L. Zagzebski (Eds.) Intellectual Virtue: Perspectives from Ethics and Epistemology (pp. 203-226). Oxford: Oxford University Press.

Robbins, P. and Aydede, M. (eds.) (2009). The Cambridge Handbook of Situated Cognition. Cambridge University Press.

Rowlands, M. (1999). The Body in Mind: Understanding Cognitive Processes. Cambridge: Cambridge University Press.

Rumelhart, D., Smolensky, P., McClelland, J., \& Hinton, G. (1986). Schemata and sequential thought processes in PDP models. In Rumelhart et al. (eds.) Parallel Distributed Processing. Cambridge, MA: MIT Press.

Rupert, R. D. (2004). Challenges to the Hypothesis of Extended Cognition. The Journal of Philosophy, 101(8), 389-428.

Sprevak, M. (2009). Extended Cognition and Functionalism. The Journal of Philosophy, 106(9): 503-527.

Trout, J. D. (2002). Scientific Explanation and The Sense Of Understanding. Philosophy of Science 69(2): 212-233.

Trout, J. D. (2007). The Psychology of Scientific Explanation. Philosophy Compass 2(3): $564-591$.

Vaesen, K. (2011). Knowledge without credit, exhibit 4: extended cognition. Synthese, 181(3), 515-529. 
Wheeler, M. (2005). Reconstructing the Cognitive World. Cambridge, MA: MIT Press.

Wilson, R. A. (2004). Boundaries of the Mind: The Individual in the Fragile Sciences:

Cognition. Cambridge: Cambridge University Press.

Wilson, R. A. \& Clark, A. (2009). How to Situate Cognition. In P. Robbins \& M. Aydede (Eds.) The Cambridge Handbook of Situated Cognition (pp. 55-77). Cambridge:

Cambridge University Press.

Ylikoski, P. (2009). "The Illusion of Depth of Understanding in Science”, in H. de Regt, S. Leonelli \& K. Eigner (Eds.) Scientific Understanding: Philosophical Perspectives (pp. 100-119). Pittsburgh University Press. 